\title{
FORMAÇÃO EM REDES DE COMPOSIÇÕES CURRICULARES COM CRIANÇAS: ENCONTROS FILOSÓFICOS
}

\author{
Kezia Rodrigues Nunes (UFES)* \\ Carlos Eduardo Ferraço (UFES)**
}

\begin{abstract}
RESUMO
Objetiva dar visibilidade às conversas com as crianças e ampliar sentidos de currículo e formação de professores(as) na Educação Infantil, motivados pela intenção de valorizar suas experiências e desejos no presente. Utiliza a pesquisa com o cotidiano por compreender a potencialidade de seus aspectos formativos para os sujeitos das escolas e das universidades na ampliação de saberes e fazeres promovida em sua relação colaborativa de autoridade partilhada. A pesquisa foi realizada no contexto das aulas de Filosofia em um Centro Municipal de Educação Infantil (CMEI) em Cariacica-ES, com crianças entre quatro e cincos anos de idade. Diferentemente do que buscam as orientações do governo atual, ao propor uniformizar uma orientação comum curricular, as redes de conhecimentos, experiências, linguagens, afecções, saberes, fazeres da escola e da vida inventadas no cotidiano escolar, em atenção aos seus sujeitos, são importante estratégia para a renovação dos currículos e dos processos de formação de professores(as) nos seus espaços-tempos de produção cotidiana.
\end{abstract}

Palavras-chave: Formação. Currículo. Crianças. Educação infantil.

\section{ABSTRACT \\ TRAINING IN NETWORKS OF CURRICULAR COMPOSITIONS WITH CHILDREN IN THE PHILOSOPHY CLASSES}

The work aims at giving visibility to conversations with children and to broaden the senses of curriculum and teacher's training in Early Childhood Education, motivated by the intention to value their experiences and desires in the present. It uses, as a theoretical and methodological contribution, the research with the everyday, due to understanding the potential of its formative aspects for the subjects of schools and universities in the expansion of knowledge and actions promoted in their shared authority relationship. The research was carried out in the context of philosophy classes of a Centro Municipal de Educação Infantil (CMEI) in Cariacica/ES with children between 4 and 5 years old. Different from what the current government's guidelines seek by standardizing on a common curricular orientation, the networks of knowledge,

* Professora Doutora do Centro de Educação da Universidade Federal do Espírito Santo (UFES). Membro do Instituto de Pesquisa em Educação e em Educação Física (PROTEORIA/UFES) e do Núcleo de Pesquisa e Extensão em Currículo, Cultura e Cotidiano (NUPEC3/UFES). Membro do grupo de pesquisa Currículos, Cotidianos, Culturas e Redes de Conhecimentos (UFES/CNPq). E-mail: keziarnunes@gmail.com

** Professor Doutor do Centro de Educação da Universidade Federal do Espírito Santo (UFES). Professor do Programa de Pós-Graduação em Educação da Universidade Federal do Espírito Santo (PPGE/UFES). Membro do Núcleo de Pesquisa e Extensão em Currículo, Cultura e Cotidiano da Universidade Federal do Espírito Santo (NUPEC3/UFES). Coordenador do grupo de pesquisa Currículos, Cotidianos, Culturas e Redes de Conhecimentos (UFES/CNPq). E-mail: ferraco@uol.com.br 
experiences, languages, affection, knowledge, school and life, made up in the school daily life, in attention to their subjects, those are important strategies for the renewal of resume and teacher training processes in their space-time of daily production.

Keywords: Training. Curriculum. Children. Children education.

\section{RESUMEN}

\section{FORMACIÓN EN REDES DE COMPOSICIONES CURRICULAR CON NIÑOS EN LAS CLASES DE FILOSOFÍA}

Objetiva dar visibilidad a las conversaciones con los niños y ampliar sentidos de currículo y formación de profesores en la Educación Infantil, motivados por la intención de valorar sus experiencias y deseos en el presente. Utiliza, como aporte teóricometodológico, la investigación con lo cotidiano, por comprender la potencialidad de sus aspectos formativos para los sujetos de las escuelas y de las universidades en la ampliación de saberes y hacer promovida en su relación de autoridad compartida. La investigación fue realizada en el contexto de las clases de filosofía en un Centro Municipal de Educação Infantil (CMEI) en Cariacica/ES con niños entre 4 y 5 años de edad. A diferencia de lo que busca las orientaciones del gobierno actual al proponer uniformizar una orientación común curricular, las redes de conocimientos, experiencias, lenguajes, afecciones, saberes, hacer de la escuela y de la vida inventadas en el cotidiano escolar, en atención a sus sujetos, son una importante estrategia para la renovación de los currículos y de los procesos de formación de profesores en sus espacios de producción cotidiana.

Palabras clave: Formación. Curriculo. Los niños. Educación infantil.

\section{Considerações iniciais}

— Nossa, que bonito! O que você está desenhando? (PROFESSORA).

- Eu ainda não sei, é que eu preciso terminar, mas ai eu te falo depois. (MENINA, 3 anos). (DIÁRIO DE CAMPO DA PESQUISA, 2011).

Em nossas pesquisas e práticas pedagógicas, temos buscado garantir às crianças o direito de viver suas infâncias nas diferentes expressões do termo, ou seja, não somente como tempo de vida da criança, mas também como possibilidade de invenção, como infâncias do viver (KOHAN, 2007), que se dá em processos de diferenciação. Composições como a da pequena garotinha da epígrafe, expressa na potencialidade dos seus três anos de idade, que se permite começar um desenho e se deixar levar pelo desejo da experiência do processo vivido, que não planeja o que vai resultar ao final, que se modifica e se mistura nas conexões com os/as outros(as) meninos e meninas e nos convida a atentar para a intensidade dos fluxos vividos.
Com isso, o objetivo central deste artigo é dar visibilidade aos movimentos infantis empreendidos pelas crianças em movimentos filosóficos no Centro Municipal de Educação Infantil (CMEI) Cantinho Feliz 1 e, desse modo, ampliar com elas os sentidos de formação e de currículo na Educação Infantil. Interessou-nos problematizar as seguintes questões: quais compreensões de formação e de currículo são agenciadas nessas composições e experiências? Que possibilidades são produzidas no contexto da Educação Infantil para que as crianças vivam problemas infantis e ampliem as redes de sentidos-produções (NUNES, 2012) $)^{2}$ com suas experiências?

1 Optamos por atribuir nomes fictícios ao CMEI e às suas crianças. Trata-se de uma das condições explicitadas no Termo de Consentimento Livre e Esclarecido, assinado pelos familiares, para autorizar a participação das crianças, em observação aos procedimentos éticos de pesquisa. No caso, "Cantinho Feliz" foi um nome escolhido em uma brincadeira realizada com os/as alunos(as).

2 Redes de sentidos-produções (NUNES, 2012) referem-se a um termo pensado para problematizar o sentido como redes em constante 
As problematizações aqui realizadas foram produzidas na pesquisa com o cotidiano (FERRAÇO, 2007), no ano letivo de 2011, com as três turmas do turno vespertino do CMEI Cantinho Feliz. Dentre as 44 instituições de Educação Infantil da Prefeitura Municipal de Cariacica, a opção por esse CMEI foi motivada por ele fazer parte do Projeto de Filosofia e Ciências Sociais, que incluía algumas unidades da Educação Infantil e do Ensino Fundamental. No momento da pesquisa, esse era o único CMEI que fazia parte do referido projeto. Além disso, também não fomos informados de outra instituição de Educação Infantil pública ou particular na Grande Vitória que incluísse esse trabalho em sua proposta pedagógica.

Filosofia para crianças ou filosofia com crianças? Essas expressões não se distinguem apenas pelo uso das preposições com e para, mas referem-se a diferenciadas propostas teórico-metodológicas. Os estudos de Riger (2006), Kohan (2007) e Olarieta (2008) perfazem uma revisão a respeito do Programa de Filosofia para Crianças, cujo pioneirismo é atribuído ao filósofo americano Mattew Lipman (1922-2011), bem como os desdobramentos de uma atividade filosófica com crianças que se diferencia de uma proposta preestabelecida. Nesse sentido, por desejarmos conhecer os processos cotidianos potencializados pelos encontros das crianças com a filosofia e não a proposta prescritiva em si, valemo-nos da metodologia das "pesquisas com os cotidianos" e de sua aproximação com a filosofia da diferença de Deleuze e Guattari (1996).

Em geral, as pesquisas com os cotidianos (FERRAÇO, 2007) referem-se às nossas escolhas metodológicas, sobretudo pelo fato de estarmos em campo sempre atentos aos saberes, fazeres, poderes e redes de relações que são tecidas pelos praticantes escolares e que conferem a essas pesquisas uma dinâmica de permanente modificação e expansão. No caso, interessou-nos acompanhar esses fios das relações entre formação e currículo, deixando-nos

produção, que não cessam de se ampliar, modificar e renovar; e como o que se evidencia nas relações entre os praticantes escolares que inventam, ao modo certeauniano, outras maneiras de ser-estar na escola. Como efeitos, ao modo deleuziano, que se destacam entre corpo e linguagem, por conexões e pelo contexto, nos não lugares dos campos discursivos. Sentidos que são produzidos nas diversas redes que envolvem o que se expressa pela e na linguagem. atravessar e atravessando suas tramas, a fim de conhecer o que era feito no miudinho da escola, especialmente no encontro com Sandro, o professor de Filosofia. Com isso, vivemos as intensidades dos cruzamentos de movimentos da vida cotidiana, como salienta Josgrilberg (2005), considerando vetores de direção, velocidade e tempo, ou seja, de diferentes espacialidades vividas nos limites de um lugar supostamente controlado, como a escola.

Na potencialidade das pesquisas com o cotidiano, fomos motivados a compor este artigo como mais um modo de resistir aos ataques que temos sofrido nas escolas e universidades sobre a legitimidade e autoridade da produção de conhecimentos, currículos e formações. Nas relações colaborativas vividas com sujeitos escolares, nossa postura em campo mantinha atenção à dinâmica de planejamentos, invenções, burlas, negociações e produções cotidianas tecidas com suas argumentações, tensões, contradições e dissonâncias (CERTEAU, 1994). Pesquisa que realiza composição com o professor de Filosofia, as professoras, a pedagoga, as merendeiras, a diretora, os familiares, as crianças e muitos outros, em uma relação de autoridade partilhada, como nos ensina Oliveira (2007).

Consideramos que este texto foi elaborado no fluxo das cenas registradas em diário de campo a partir de dois procedimentos metodológicos que se destacaram na pesquisa com o cotidiano: o mergulho e as conversações com crianças. Ao mergulhar com todos os sentidos (ALVES, 2001), rompendo com o paradigma centrado no olhar, buscamos ampliar nossa sensibilidade para as diferentes demandas curriculares com os sujeitos da instituição, participando da acolhida, lanches, visitas pedagógicas ao supermercado, ensaios, contação de histórias, atividades, brincadeiras, exposições dos seus trabalhos, planejamentos docentes, dentre outros. Desse modo, a escrita não narra apenas o que vimos, mas o que escutamos, sentimos, tocamos, planejamos e o que irrompeu no cotidiano escolar. Na mediação com Sandro, a conversação com as crianças foi um movimento utilizado para produzir dados e sentidos de currículos. Com Certeau (1994), reconhecemos que não existem proprietários individuais em uma conversa, por se tratar de uma trama tecida por diferentes e simultâneas referências. Essa rede não toma como 
foco a dimensão linguística, mas a experiência (LARROSA, 2002), e também não se esgota no dito, pois se vale do que dele se retira infinitamente.

Com os sujeitos escolares, e não sobre ou para eles (ALVES, 2001), temos ampliado e conferido visibilidade aos currículos, aos processos de formação que nos constituem e à produção de conhecimentos vividos nas redes que compõem os cotidianos dentro e fora da escola. Este texto se expressa como desejo de conferir visibilidade aos saberes e fazeres docentes e aos direitos da criança de brincar, educar, pensar, produzir e viver uma educação pública e de qualidade.

\section{Pistas para pensar a formação e o currículo como rede de relações}

Os trabalhos que compõem algumas paredes do referido CMEI, produzidos com as pegadas das crianças, convidam-nos a pensar em um sentido clichê para a formação e para o currículo que se guiaria por uma trilha, um caminho, um rumo para a educação e para a vida das crianças e do país. Um sentido de caminho como o que está presente na etimologia da palavra currículo (scurrere), que indica um percurso, uma pista de corrida, um trajeto a ser seguido (GOODSON, 1995; TERIGI, 1996). Se tivermos dúvidas quanto ao seu formato, se pisarmos fora da pista indicada, diferentes prescrições ${ }^{3}$ nos indicam a necessidade de retomar esse caminho, prestigiando e/ou escolhendo um tipo de rota.

Apesar de não negar os inúmeros mecanismos de controle encontrados nas escolas, as pesquisas com os cotidianos buscam problematizar a necessidade de se diminuir a ansiedade em relação ao lugar de chegada, ao fim de um processo de formação, por exemplo, para se dedicar aos processos vividos, às

3 No contexto de extensão do Ensino Fundamental de oito para nove anos de curso, o Ministério da Educação tem divulgado uma série de orientações que delimitam o território para a formação e o currículo da Educação Infantil, tais como: Diretrizes Curriculares Nacionais para a Educação Infantil (BRASIL, 2010), Critérios para um Atendimento em Creches que Respeite os Direitos Fundamentais das Crianças (BRASIL, 2009a), Indicadores da Qualidade na Educação Infantil (BRASIL, 2009b), Orientações sobre Convênios entre Secretarias Municipais de Educação e Instituições Comunitárias, Confessionais ou Filantrópicas sem Fins Lucrativos para a Oferta de Educação Infantil (BRASIL, 2009c), Política de Educação Infantil no Brasil (BRASIL, 2009d) e, ainda, os Fundamentos Pedagógicos e Estrutura Geral da Base Nacional Curricular Comum (BRASIL, 2017). experiências e às composições que fazem dos currículos e das formações movimentos que se alteram a cada momento. Menos importância para o fim, o produto, e mais atenção para o que se passa no meio, intermezzo (DELEUZE; GUATTARI, 1996).

Com isso, nossa perspectiva de entendimento sobre formação e currículo, em suas múltiplas relações com as crianças-infâncias, situa-se em meio aos movimentos rizomáticos que acontecem por dentro uns dos outros e que nos impedem de situar quando se está falando de currículo ou de formação, uma vez que ambos se proliferam e ramificam em linhas que se cruzam, sempre pelo meio. Como afirmam Deleuze e Guattari (1996, p. 37), "[...] um rizoma não começa nem conclui, ele se encontra sempre no meio, entre as coisas, inter-ser, intermezzo. A árvore impõe o verbo 'ser', mas o rizoma tem como tecido a conjunção 'e... e... e...".

Oposto a uma estrutura que se define por um conjunto de pontos e posições, por correlações binárias entre esses pontos e relações biunívocas entre essas posições, o rizoma é feito somente de linhas: linhas de segmentaridade, de estratificação, com dimensões, mas também linha de fuga ou de desterritorialização como dimensão máxima segundo a qual, seguindo-a, a multiplicidade se metamorfoseia, mudando de natureza (DELEUZE; GUATTARI, 1996).

Assim, as diferentes rotas vividas nos processos de formação e de produção curricular com as infâncias também tensionaram modos singulares de nos relacionar com esses mesmos processos e suas possíveis possibilidades de chegada. Contudo, a necessidade de controle quanto ao objetivo final tem uma grande pretensão: o desenvolvimento integral da criança, assim como assumem as Diretrizes Curriculares Nacionais para Educação Infantil (BRASIL, 2010, p. 12), que trazem uma definição para esse território:

Currículo: Conjunto de práticas que buscam articular as experiências e os saberes das crianças com os conhecimentos que fazem parte do patrimônio cultural, artístico, ambiental, científico e tecnológico, de modo a promover o desenvolvimento integral de crianças de 0 a 5 anos de idade.

Existiria um caminho único e eficiente que permitiria que as crianças mobilizassem seus conhe- 
cimentos em articulação ao patrimônio que temos acumulado a fim de promover seu desenvolvimento integral? Ao mobilizar nossa atenção aos sentidos produzidos pelas crianças, talvez nossa rota mude o foco, porque elas trazem a intensidade de suas vidas para o que buscamos categorizar como conhecimento escolar necessário e, ainda, para o que pensamos ser formação e currículo.

Com as Diretrizes Curriculares Nacionais para a Educação Infantil (DCNEI) (BRASIL, 2010), compreendemos que os conhecimentos das crianças não são desvalorizados, mas existe um modo indicado como necessário de reuni-los ou dialogar com eles: a partir do "patrimônio cultural, artístico, ambiental, científico e tecnológico". Ele é o eixo tomado como referência nas prescrições curriculares e de formação, que assume um modo objetivo de conduzir o caminho da escolarização.

Nessa e em outras prescrições curriculares do Ministério da Educação disponíveis em seu website, diferentes formatos são assumidos. Referimo-nos a aproximadamente 40 documentos. Parte deles possui fins de orientação e, recorrentemente, realizam uma historicização das políticas públicas nacionais. Outra parte possui caráter mandatório e a outra trata de relatórios. Ao considerar seus diferentes formatos e objetivos, podemos destacar a busca de pluralidade de discussões e elaborações no registro de diferentes atores envolvidos em seus processos de produção. Dentre eles, podemos destacar: o Instituto Nacional de Estudos e Pesquisas Educacionais Anísio Teixeira (INEP), a Secretaria de Educação Básica do Ministério da Educação (SEB), o Fundo Nacional de Desenvolvimento da Educação (FNDE), a União Nacional dos Dirigentes Municipais de Educação (UNDIME), a Confederação Nacional dos Trabalhadores em Educação (CNTE), a Associação Nacional de Pós-Graduação e Pesquisa em Educação (ANPEd), o Movimento Interfóruns de Educação Infantil do Brasil (MIEIB) e a Rede Nacional Primeira Infância (RNPI).

Diferente movimento tem sido empreendido na elaboração da última versão da Base Nacional Comum Curricular (BRASIL, 2017), que, de modo ainda mais regulatório, busca destacar atitudes, habilidades e competências esperadas para crianças e para seus profissionais. Nesse contexto, outros sujeitos e instituições protagonizam essa compo- sição com aspectos marcadamente empresariais. Dentre eles, destacamos a Fundação Itaú Social, a Fundação Lemann, a Fundação Roberto Marinho, o Instituto Unibanco, o Instituto Ayrton Senna, o Instituto Natura. Nessa parceria, quais teorias e metodologias assumiremos no trabalho com crianças e na formação de seus professores(as)? De que modo o tratamento igual dos diferentes sujeitos em seus contextos desiguais de vida pode contribuir para potencializar seus processos de conhecimento e a formação de professores(as)? Já temos identificado a serviço de quem estão as contrarreformas atuais da Educação e o modo como os empresários têm comemorado suas aprovações.

Assim, compreendemos que a prescrição de currículo que, fatalmente, produz um sentido correspondente de formação prioriza um modo de produzir conhecimento que busca informar ou, ainda, formar, no sentido de dar uma forma, de formatar, ou seja, trazer informações historicamente acumuladas e socialmente validadas para o trabalho com crianças de até cinco anos de idade. Isso é pretendido ao se priorizar o que deve ser ensinado e perseguido como alvo nessa pista de corrida para a formação-currículo, que trata do caminho da escolarização que se inicia com os bebês. Formação como preparação de professores(as) para o trabalho com uma prescrição curricular universal, como modo de ensinar crianças desde a Educação Infantil a se preparar para o nível subsequente, até a aprovação (de um número cada vez menor, dadas as reduções de investimento) no Ensino Superior. Formação em atenção ao conteúdo, aos níveis, às metas, mas não aos sujeitos e a seus contextos.

Essas inferências nos ajudam a tensionar questões postas por Carvalho (2012): por que devemos lamentar a ordem estabelecida e celebrar a produção cotidiana dos currículos vividos nas escolas? Talvez porque a nossa relação cotidiana com as crianças nos tem feito problematizar as verdades-modelos que assumimos tanto para o conhecimento quanto para a formação e o currículo. Suas múltiplas linguagens nos perguntam: por quê? Por que em fila e sentados, quando eu quero deitar para desenhar com os colegas? Por que horários tão definidos me impedem de continuar criando e brincando? Por que minhas respostas não podem ser consideradas válidas? Os/as professores(as) 
também têm perguntado muito: por que precisamos cumprir jornada dupla ou tripla na escola? Por que, mesmo tão envolvidos, nossa profissão é desvalorizada? Por que não podemos nos reunir com os/ as colegas da escola para pensar o nosso trabalho, buscando potencializar processos coletivos de formação a partir das experiências vividas nas escolas?

Com a Filosofia da Diferença de Deleuze e Guattarri (1996), buscamos outras lógicas, outros sentidos, para nos aproximar das crianças, porque elas conectam modos infantis para viver a educação, elas se lançam ao novo e que por isso podem ser vistas como sujeitos da experiência, ao modo de Larrosa (2002). Consideramos que essas são características de quem toma a experiência como ato de experimentar, de experienciação, de se lançar ao imprevisto, de tratar do que o atravessa, um modo crianceiro do povo-criança. Povo em sua multiplicidade ao invés de um indivíduo auto-centrado e padronizado quanto às suas características e possibilidades afetivas, cognitivas e motoras.

É sua força criadora e desestabilizadora que movimenta as certezas acumuladas pelo sujeito experiente, que não vê a experiência como criação de possibilidades, mas a relaciona com o que tem acumulado com a suposta segurança de seu planejamento-prescrição. Essa paradoxal relação, ao modo de Deleuze (2009), reúne pela experiência formas diferentes de se comportar e de viver: de um lado, os sujeitos que percorrem novos caminhos; do outro, os sujeitos que carregam o peso acumulado nos caminhos já percorridos e dele se valem para se fundamentar e se justificar. Restaria aos iniciados no contexto educacional a tarefa de tensionar outros modos intensivos de produzir conhecimentos, de dar vazão a desejos produtivos, de se lançar a outros possíveis, de criar outros traçados para um currículo-experiência-formação?

Nesses termos, fomos motivados à busca de uma janela, como a que escreve Leal (2009), que desse visibilidade às múltiplas infâncias do aprender vividas nos cotidianos escolares, às diferentes experiências produzidas pelas crianças, aos modos de se relacionar com as atividades propostas e com os espaços-tempos institucionalizados, aos movimentos criados por elas que possam estar sendo invisibilizados por uma tendência homogeneizadora de ver a escola. Ao cartografar esses movimentos, voltamo-nos para as redes de sentidos-produções que ganhavam contorno na dinâmica dos processos de formação e dos currículos realizados (FERRAÇO, 2005).

Entendemos por formação-currículo, para além das prescrições instituídas, tudo o que é vivido cotidianamente nos seus diferentes espaços-tempos de produção, que mantém relação com a confluência de múltiplas demandas da vida cotidiana: a rotina que se reinventa todos os dias nas instituições escolares, os saberes-fazeres das crianças e dos adultos, o aparato didático-pedagógico mobilizado e produzido, as opções teórico-metodológicas, as propostas e projetos escolares de diferentes níveis, os improvisos, as contradições, as documentações, as invenções, as afecções, as conversações, as narrativas-imagens, enfim, as múltiplas redes de sentidos-produções. Assim, como propõe Ferraço (2007, p. 75), pensar os currículos e as formações implica, antes de tudo, “[...] viver os cotidianos das escolas, o que inclui, além do que é formal e tradicionalmente estudado, toda a dinâmica das relações estabelecidas com os seus sujeitos praticantes".

Formações e currículos realizados sempre no plural, porque não existe um único sentido para concebê-los e vivê-los em cada sala de aula, em cada escola, em diferentes níveis de ensino. Neste momento, o que se destaca nessa rede de sentidos-produções é a ideia de "multiplicidade" que nos força a pensar e a superar as tradicionais imagens-clichê aprendidas para a formação e o currículo e, ainda, os modos padronizados de viver a escola. Tratamos de movimentos que buscam desconstruir as estruturas, as regras, os modos de controle e, com isso, potencializam redes de relações e de movimentos que ampliam os sentidos de currículo e de formação que fogem a essa demarcação, que apontam para uma antidisciplina e que fazem valer a multiplicidade e a diferença.

Ainda com Deleuze e Guattari (1996), compreendemos que esses diferentes fluxos, compostos por linhas molares, moleculares e de fuga contribuem para a emergência de novas concepções de infância na Educação Infantil, que estão sendo gestadas cotidianamente e que precisam ganhar visibilidade. Assim, problematizamos os diálogos entre as atividades propostas pelos(as) professores(as) e as experiências das crianças em seus agenciamentos 
infantis. Como em outro momento de pesquisa e de formação coletiva,

Nosso interesse residiu em tentar compreender como os/as alunos/as estavam negociando esses diferentes sentidos e, sempre que possível, provocar o debate, desestabilizar opiniões fechadas, desconstruir diagnósticos definitivos, ou seja, criar linhas de fugas para o pensamento, ampliar as possibilidades de entendimento e de conhecimento daquilo que, no momento, estávamos chamando de currículo. (FERRAÇO; NUNES, 2011, p. 383).

A respeito da questão que problematiza as compreensões de currículo e de formação, podemos dizer que essas noções precisam ser consideradas em suas relações "com” as crianças e não apenas "para" as crianças, tendo em vista a necessidade de se considerar os diferentes agenciamentos, saberes, fazeres, poderes e afecções que as compõem. Estamos atentos aos tensionamentos presentes nas relações entre os seus diferentes espaços-tempos de produção (escola, universidade, secretarias, residências, associações...), para as demandas dos diferentes corpos (crianças, professores(as), merendeiras, familiares, secretários(as)...) que deles fazem parte, e para a potencialização dos elementos incorporais (desejos, sentidos, paixões, expressões...) que os compõem.

Ao tomar a criança com centralidade nesses processos, currículo e formação também se revelam como territórios de disputas e de poder, onde um dos desafios continua sendo dialogar com os seus corpos e nos colocar no fluxo da noção de devir. A esse respeito Deleuze e Parnet (2004, p. 12-13) afirmam:

Devir nunca é imitar, nem fazer como, nem se conformar a um modelo, seja de justiça ou de verdade. Não há um termo do qual se parta, nem um ao qual se chegue ou ao qual se deva chegar. Tampouco dois termos intermutáveis. A questão 'o que tu devéns?' é particularmente estúpida. Porque à medida que alguém devém, aquilo que devém muda tanto quanto ele próprio. Os devires não são fenômenos de imitação, nem de assimilação [...]. Uma conversa, poderia ser isso. Simplesmente o traçado de um devir [...]. Os devires são o que há de mais imperceptível. São atos que só podem estar contidos numa vida e expressos num estilo.

Mesmo com a nossa intenção de preparar tudo para elas, a relação com elas ainda precisa de investigação, problematização e experimentação. Compreendemos que o modelo escolar atual, maioritário, superabunda em sujeitos (turmas numerosas, escola com muitas turmas, diferentes especialidades da educação), em produção científica (congressos, periódicos, monografias, dissertações, teses, documentos curriculares, livros), em experiências acumuladas historicamente. Contudo, ainda carece de permanente atualização a respeito das necessidades minoritárias das crianças, desconhecidas pela falta de debate e atenção, de espaços-tempos para ouvi-las, de projetos que considerem a autoria de suas composições e linguagens.

\section{Pistas sobre as produções com as crianças...}

Nos encontros às terças-feiras, mediados pelo professor Sandro, acompanhamos a composição dos processos de formação e dos currículos que foram realizados (FERRAÇO, 2007) com as crianças: a escolha de temas problematizadores para a roda de conversa, as atividades em que ele buscava provocar essas discussões, as brincadeiras que conferiam sentidos ampliados a esse trabalho, os diferentes movimentos dos planos no encontro com as crianças em atenção não às informações e/ ou conteúdos prescritos, mas, sobretudo, aos seus modos de pensar.

A distinção que Deleuze estabelece entre "corpos" e "incorporais" nos permite problematizar a diferença que existe entre saber e pensar. Enquanto o saber diz respeito à informação e seu acúmulo, à memória, o pensamento tem a ver com o acontecimento, com o sentido, e o sentido não é algo que se possui, mas uma relação que se estabelece (LÓPEZ, 2008).

Em uma de suas aulas (30/04/12), Sandro reservou o vídeo "Os Vegetais". Tratava-se de um desenho animado cujos personagens que compõem as histórias são vegetais. O episódio que ele selecionou problematizava tanto a nossa relação com o consumo, quanto com os produtos e os alimentos.

A personagem principal desse episódio, Madame Blueberry (por indicação das crianças, optamos por chamá-la Dona Uva), gastava todo o seu tempo e dinheiro comprando, em um grande supermercado, tudo o que conseguia carregar. Ela sentia falta 
de alguma coisa, que ainda não sabia o que era e esperava que, em suas compras, pudesse descobrir. A despeito de tudo comprar, não conseguia alcançar seu objetivo. Em certas cenas, algumas personagens a fizeram compreender que o que ela procurava era algo incorporal, algo que não possuía valor como objeto, algo que não se poderia alcançar com dinheiro, como ela estava tentando incansavelmente. Ela estava em busca da felicidade.

Em nossas redes de conversações com as crianças, a intenção também era tratar da felicidade, dos bons encontros que ampliam a vida, do que as deixa felizes. Quando perguntadas sobre o que ou quem as faziam felizes, um tecido oral se compôs:

Dinheiro. Amar. Chocolate. Brinquedo. Meu irmão. Brincar. Meu pai e minha mãe. Passear. Os amigos. A casa arrumada, a Dona Uva tava triste porque a casa dela tava uma bagunça. Vida nova. Quando eu tô rico, igual ao Pica-Pau, aí eu fico feliz. Eu gosto quando eu tenho muito dinheiro. Eu gosto de dar um abraço na minha filha [pesquisadora]. Um abraço, só isso? É... É que eu gosto de dar abraço e beijo. E eu até gosto de abraçar e beijar minha mãe, quando eu chego da escola. Fico feliz quando chego em casa, tomo banho, deito no sofá e assisto à TV. (DIÁRIO DE CAMPO DA PESQUISA, 2011).

Em nossa roda de conversas nos divertíamos com a rede de sentidos-produções criadas para a palavra felicidade, que ora fazia conexão com o vídeo, ora com os diferentes contextos de nossa vida cotidiana, ora com outros desenhos assistidos, ora com as histórias fabuladas, ora com o que não nos trazia felicidade.

Isso mesmo. Para nossa surpresa, falar sobre a felicidade moveu as crianças a pensar um problema, o que nega esse estado para sua vida, o que produz momentos de infelicidade. Foi com muita dificuldade que conseguimos conversar, porque nossa preocupação também estava em organizar o grupo para conseguir ouvir a todos. Tarefa difícil conter as redes de conversações, de pensamentos, de conexões. Todavia, em diferentes momentos, elas insistiram. Desviando-se do grupo, era como se algumas viessem nos confidenciar segredos:

Tia, tia, tia, aí eu quero falar. Peraí, o colega tá falando. Tia, tiiiiiiiia, eu quero falar. Aaaaaaaah... Tia, meu pai bebe. Bebe cachaça e jurubeba. Por isso o dinheiro dele acaba. Ele sempre fala que está com fome, ou que 'esqueceu' de almoçar. Tia, meu pai é ruim, ele não compra nenhuma bala para mim. Ele tem dinheiro, mas não compra. Tia, meu pai bebe e fica muito doido. Ele fica tão doido que um dia ele bateu com meu violão no vidro da mesa. Ele fica doido. Tia, eu fico triste porque meu pai não me escuta. $\mathrm{Eu}$ falo com ele, mas ele só fica com os amigos no bar. Ele nem liga pra mim. (DIÁRIO DE CAMPO DA PESQUISA, 2011).

O vídeo e as redes de conversações foram utilizados como provocação para a criação de um problema singular: o sentido que a felicidade possui para as crianças. Talvez nossas questões implícitas fossem: o que é? Como é? Como alcançá-la? Como se sente com ela? Talvez as questões das crianças sejam: por que não posso estar com ela o tempo todo? O que fazer para apagar o que não me traz felicidade? Essa experiência nos mostra que o trabalho de Sandro não almejava produzir uma proposta curricular com a intenção de modelizar as crianças, mas buscava produzir com elas outros modos de pensar o currículo, imagens infantis para revigorá-lo, infâncias que educassem o currículo, tal como anuncia Carvalho (2012).

Também foi a partir do modo como o vídeo, as conversas e as experiências das crianças se articularam e vibraram em seus corpos que compreendemos que esse momento intensivo se aproxima do conceito de problema discutido por López (2008). Para ele, um dado conceito, uma informação, uma pergunta ou mesmo uma resposta só fazem sentido em relação a um dado problema: "Se faltar o problema, falta a força, falta a necessidade; se faltar o problema, não há como e o que pensar" (LÓPEZ, 2008, p. 94).

No trabalho filosófico com as crianças, López (2008) trata da importância da criação de problemas próprios, que tenham relevância para as crianças por serem criados por elas. Nas conversações, nos textos escolhidos, nos temas eleitos, é o modo como as crianças se relacionam com os problemas e a maneira como os criam que confere sentido a essa experiência de pensamento.

Essa experiência intensiva, que desloca o pensamento a criar os próprios problemas, que nos força a pensar pelo que nos é heterogêneo, por vezes é denunciada por não fazer parte da escola. Dado o caráter sistematizador e divulgador do 
acervo cultural, a escola tem sido criticada por não alcançar, em seus conteúdos redes de sentido que possam mover crianças, adolescentes e jovens na contemporaneidade.

López (2008) analisa a produção de conhecimento na escola a partir de dois eixos complementares. O primeiro, que chamamos de eixo intensivo, relaciona-se com a experiência, a problematização, o modo como o sujeito confere sentido ao conhecimento. Um eixo que se compõe em uma linha de intensidade vertical, que busca conferir sentido no encontro com os signos, na possibilidade de permanente invenção do tempo aiônico.

O segundo, que chamamos de eixo cronológico, mantém relação com a acumulação cultural do conhecimento, com as informações veiculadas historicamente, com o compromisso em garantir o acesso a essa bagagem histórica e cultural. Esse eixo se compõe em uma linha cronológica horizontal e suas escolhas são organizadas com base no tempo chrónos.

Esse eixo dialoga com a opção dessa e de outras instituições quanto à organização de experiências e conhecimentos na Educação Infantil, pautadas pela definição de uma rotina que define previamente tempo e espaço em horário escolar semanal para suas diferentes atividades. Trata da referência que dialoga com o Ensino Fundamental, com professores especialistas em..., as aulas de..., a hora de... tal como criticava Sayão (1997). Assim, o encontro com Sandro possuía um formato que era definido previamente nas turmas como aulas de Filosofia, e aconteciam duas vezes por semana em cada turma. O mesmo se dava quanto aos momentos de lanche, janta e pátio. Haveria outra possibilidade de encontros na Educação Infantil para além das rotinas que sobrepujam a intensidade do desejo e das experiências das crianças? Quais outros modos possíveis para potencializar experiências com diferentes sujeitos e profissionais que ampliem a compreensão centrada em disciplinas?

A crítica ao modelo disciplinar considera que os tempos de conversas, atividades e brincadeiras com as crianças não se organizam em uma temporalidade cronológica, do tipo chrónos, que pode ser organizado em sequência linear de passos. É uma relação com as coisas e processos, do tipo áion, que mergulha na relação sem planejamento do que pode ser ou tornar-se, uma vez que o interesse está na experiência e na diferença que se produz.

A constante busca por uma relação entre esses eixos confere ao conhecimento produzido na escola redes de sentidos-produções diferenciadas para os alunos. Essa relação indica o modo como esses conhecimentos vibram nos corpos dos sujeitos e proporcionam diferentes usos em suas artes de criar problemas, de produzir sentido. Eixos que não se definem apenas pelo que os diferencia, mas pelo que reúnem em suas diferenças. Eixos que só existem nessa relação.

A educação se desenvolve nesses dois eixos ao mesmo tempo. Não é possível ficar inteiramente num deles. O que é importante destacar é que o sistema educativo, em termos gerais, por não ter advertido o caráter de acontecimento do pensamento, tem tentado atrelar de modo permanente as palavras a sentidos únicos e, assim, privilegiado o eixo cronológico em detrimento do eixo intensivo (LÓPEZ, 2008).

A intensidade da experiência buscada por Sandro para suas aulas permitia uma flexibilidade com relação à disposição das crianças nos espaços-tempos do CMEI, que não se colocavam sempre em filas ou sentadas nas carteiras, mas também se organizavam em rodas de conversas e de atividades na sala de aula e no pátio. A presença de Sandro provocava um desassossego nas crianças, porque nessa aula era possível sentar ou deitar para desenhar, dançar sem seguir uma coreografia e estar no pátio. Essa era a aula que tornava outras experiências no pátio possíveis.

As crianças nos cobravam, mostravam-se ansiosas para habitar outros espaços-tempos no CMEI. Era como se ao Sandro fosse destacada uma condição que não estava para as outras professoras, pois elas estavam fadadas ao cumprimento de tudo o que o eixo cronológico poderia lhes cobrar, em especial, as obrigações escolares com as demandas de leitura, escrita e matemática. O lugar que ele ocupava permitia uma pausa para respiração, uma flexibilidade com relação aos espaços do CMEI, uma intensidade que se diferenciava a partir das redes de sentidos-produções tecidas pelas crianças. Entretanto, apenas a ele e às suas aulas essa condição se torna possível? Outros currículos-formações-experiências têm sido tecidos nessa 
escola? O que tem vazado da organização disciplinar e dialogado com a vida dos sujeitos escolares?

Sandro organizava suas aulas deixando muitas brechas para as crianças, muitos vazios a serem preenchidos. Em um desses encontros, construiu fantoches de ovelhas com bolas de isopor para uma adaptação da história "Sai pra lá", da autora Ana Terra. As crianças se divertiram com os fantoches e com o enredo que tratava das singularidades de cada ovelha diante da aparente homogeneidade que elas apresentavam na brancura de seus novelos.

Também apresentou o livro, composto por belas imagens, que circulava pelas mãos das crianças e disputava sua atenção com o painel onde os fantoches se apresentavam. Algumas crianças se levantavam para conferir como nos posicionávamos junto com Sandro atrás do painel; outras chegavam bem pertinho das ovelhas para ver como elas se mexiam; outras se aproximavam a cada vez que modificávamos as vozes; outras queriam conferir o baú de bonecos que participariam da cena. Quando convidados a fabular suas histórias com os fantoches, a atividade ganhou novo brilho. $\mathrm{Na}$ turma da professora Rosi, com crianças de quatro anos, um menino e uma menina escolheram fantoches de vovô e de menino. Ele contou a história da Dona Preguiça: "Era uma vez uma menina que tinha muita preguiça, era a Dona Preguiça: 'Ai, que preguiça de levantar, eu quero dormir mais um pouquinho'. 'Levanta, Dona Preguiça, já tá na hora de acordar'”. (DIÁRIO DE CAMPO DA PESQUISA, 2011).

Em outro momento, Sandro distribuiu a turma em grupos sentados no chão, dispostos em volta de uma folha de cartolina, para que desenhassem a história com tinta guache. Contudo, não consistia nos objetivos de Sandro afirmar uma transcrição da história, mas permitir às crianças outras experiências, tais como: o trabalho com a tinta, a experimentação desapressada com essa textura, o relaxamento corporal ao pintar na posição que escolhessem (sentados, debruçados, deitados, balançando as pernas).

Eventualmente, as crianças pintavam ovelhas. Contudo, a experiência extrapolava esse desenho: pintavam outras coisas, pintavam novos desenhos sobre o que haviam acabado de formar, trocavam as tintas com os colegas, visitavam os outros grupos.
Sandro parecia não se importar muito com um desenho final, com o que poderia ser bonito de expor. O diário de campo nos ajuda a recuperar e compor outros sentidos-produções para essa experiência.

Ao dividir a turma em grupos de quatro ou cinco crianças para pintar com guache na cartolina, presenciamos suas múltiplas negociações, seus modos de se relacionar com a proposta do professor. Trocas de tintas, trocas de espaços no chão, trocas de grupos, trocas de papel para limpar o pincel. Tentar esconder dos colegas os potes com tinta também era necessário para conseguir desenhar antes que a tinta acabasse. Em um dos grupos, os meninos repetiam o movimento de passar o pincel de modo constante. Deixavam-se mover pela experiência e se entregavam a ponto de não perceber que o papel começava a rasgar. Alguns encharcavam o pincel de tinta e se colocavam na experiência de ziguezaguear na folha, em um movimento de vaivém que parecia retirá-los daquele lugar.

Aos poucos, o alvoroço do início da tarefa diminuía.

'É uma estratégia terapêutica. É essa experiência sensível, do relaxamento, da pintura com o pincel, com a mão. A distração com esse meio, com o copo de água que limpa o pincel, o prazer da atividade que acho interessante', dizia o professor. 'Tia, é tão legal, né?' 'O quê?', perguntei. 'Brincar com tinta.' (DIÁRIO DE CAMPO DA PESQUISA, 2011).

Se a proposta foi indicada como atividade complementar à história de fantoches da semana anterior, não foi assim vivida por todas as crianças. Também não foi cobrada pelo professor, que queria permitir às crianças viverem experiências de pintura para além do lápis de cor e do preenchimento contido em desenhos específicos. Não privilegiava um eixo intensivo ou cronológico, mas os modos de relacioná-los pareciam interessar.

Em outro grupo, um movimento diferente era realizado com uma criança que limpava o pincel no copo de água. Um roda-roda que não tinha fim, nem direção, nem final. Não era só a limpeza do pincel que a motivava, mas o movimento da água colorida no copo, o movimento realizado pelo pincel, a repetição, a experiência de se colocar em movimento. O copo com água ganhou a mesma importância que as tintas. Era tão disputado quanto 
elas. Aágua no copo não parava de girar. "Tia, quer leitinho?", perguntou um dos meninos. "Leite com o quê? Ele tá puro?", perguntei. "Tá com Toddy. Meu leite está geladinho". "Hum, bebi muitos copinhos!” (DIÁRIO DE CAMPO DA PESQUISA, 2011).

Nas práticas curriculares que tomam a experiência como referência para formação, as atividades não são cumpridas, não são obedecidas, não tratam apenas do conhecimento de um conteúdo, mas de um modo particular-coletivo de estar na escola. Nesse movimento, os modos de viver intensivamente experiências com pinturas e texturas pareciam ser mais relevantes do que o produto do trabalho das crianças, do que o objetivo a ser cumprido na atividade. Nas conexões que fazem no contexto da aula de Sandro, importa agenciar modos de experimentação e de movimentação nas redes que compartilhamos no cotidiano escolar.

Nem sempre existe uma lógica adultocêntrica para explicar as aproximações entre as crianças. Elas partilham em suas brincadeiras modos particulares de estar no grupo sem estar com o grupo. Cada criança movendo-se por suas intensidades e desejos particulares-coletivos. Os agenciamentos produzidos pelas crianças sobre a maneira como desejam viver esse lugar nos interessam, porque trata dos modos como a escola se atualiza cotidianamente e nos mostra não o que dizem sobre ela, mas o que ela tem se tornado nessas redes de sentidos-produções, conversações, afetos e experiências. Assim como discute Carvalho (2011, p. 113),

[...] é necessário evitar a mutilação da alegria de aprender, do prazer de criar nas salas de aula das escolas e, nesse sentido, devemos explorar o currículo como um 'acontecimento' vivido nele mesmo. $\mathrm{O}$ currículo muda à medida que nos envolvemos com ele, refletimos sobre ele, consideramos sua complexidade tecida em rede de conversações e agimos em direção à sua realização, buscando, nos afetos e afecções, a potência inventiva de um currículo não burocratizado e normalizado.

Os sentidos de infância e de Educação Infantil expressos pelas crianças não parecem se relacionar apenas com o conhecimento garantido na prescrição curricular, com as pesquisas acumuladas sobre determinado tema, com a comprovação de alguma equação matemática ou física. As experiências vividas pelas crianças conferem novos contornos para as atividades escolares de acordo com as redes de sentidos-produções que compõem suas relações com os/as professores(as) e com os/as alunos(as). Para Carvalho (2012, p. 20), “[...] um sentido importante da educação de nosso tempo pode ser visto na restauração da infância como criação de situações propícias à experiência, na geração das condições para que sejam possíveis, entre nós, outro modo infância e outra experiência".

As conexões estabelecidas entre adultos, entre crianças, entre crianças e adultos são agenciadas como linhas de diferentes segmentaridades. O que é produzido nessas relações interfere no que o outro pensa, organiza, determina. Linhas, fluxos, segmentos. O movimento de criar problemas a partir do que desestabiliza as crianças também movia o pensamento a compartilhar explicações a respeito do que a elas interessava. Nos momentos cartografados na sala de aula, no pátio ou no refeitório, ainda nos divertíamos com nossas redes de conversações e explicações. Também registrei as compreensões de minha filha Isabela, que às vezes participava das conversas com as crianças em visita ao CMEI:

Você sabe como nasce o choro? É que, quando a gente está triste, sai uma água do olho que se chama lágrima. Essa água vai saindo do cho-ra-do. No chorado é que sai a lágrima. No chorado. (ISABELA, 4 anos).

Você sabe como pega catapora? É assim: o osso tem um monte de bolinhas. Essas bolinhas vão saindo do osso e vão subindo para a pele. Quando elas chegam aqui em cima, elas estouram e viram catapora. É assim. (ANA, 5 anos).

Que tal a gente fazer assim: a gente conversa, come só um pouquinho e vai conversando mais? Que tal? (CRIS, 4 anos).

Quando a gente mata uma minhoca ou uma cobra, sabe o que acontece? Ela xinga pelo rabo. Ela grita por dentro do rabo: Ahhhhh! (BEATRIZ, 6 anos).

Ela não está grávida. Você confundiu, acho que foi a comida na barriga dela que mexeu. Ela precisa comer bastante para ficar grávida. Faz assim: dá três colheres de comida no almoço e um pouquinho desse remédio que à noite ela vai estar grávida. (ISABELA, 4 anos). 
Eu te amo do tamanho do céu, do tamanho do mar, do tamanho do espaço, lá onde passa os foguetes, do tamaaaanho da parede! (ISABELA, 4 anos). (DIÁRIO DE CAMPO DA PESQUISA, 2011).

A respeito da segunda questão anunciada na introdução deste trabalho sobre as possibilidades produzidas no contexto da Educação Infantil para que as crianças vivam problemas infantis e ampliem as redes de sentidos-produções com suas experiências, podemos dizer que muito tem sido produzido nos diferentes espaços-tempos escolares. Contudo, talvez essas problematizações fiquem restritas aos corredores das escolas, secretarias, universidades, onde suas histórias são discutidas, comentadas e ilustradas. Maior espaço tem sido dado às experiências que fazem relação com o currículo maioritário ou com o eixo cronológico, que contemplam respostas únicas e modos de produção de conhecimento que valorizam mais o objetivo final do acerto do que a experiência da busca por respostas.

Assim, nossa narrativa esteve centrada no encontro com esses fluxos nos currículos-experiências-formações no cotidiano escolar, em composição com o eixo intensivo. Por meio das conversações, compreendemos que as lógicas infantis percorrem diferentes caminhos, não condicionadas apenas à modelação das explicações dos(as) professores(as) ou do conhecimento científico. Os trechos do diário de campo fazem conexão com os modos de afetar e ser afetado pela felicidade, com os agenciamentos brincantes produzidos com a literatura, com os saberes e fazeres que narram suas vidas, com as conversações que ampliam nossos modos infantis de experimentar permanentemente modos de viver a escola. No mergulho com todos os sentidos no cotidiano escolar, na companhia das crianças e dos(as) professores(as), foi possível dar visibilidade a essa trama minoritária sem desqualificá-la como menor.

Para a professora Mathilde, que trabalhava com as crianças de cinco anos, essas histórias nos ajudam a compreender como as crianças organizam modos de pensar diferentes dos adultos. Em suas redes de produção de sentidos, fazem gaguejar a linguagem que busca padronizar modos adequados de explicar a escola. Certamente, como nos ensina o poeta Manoel de Barros (1993, p. 5), “As coisas que não têm nome são mais pronunciadas por crianças". Elas não se importam com o que nos parece razoável, estão mais dispostas a inventar possibilidades que se distanciam de nossas fundamentações.

Entendemos que isso não basta, o poder de criação não se encontra apenas nas crianças. Sozinhas talvez não façam muita coisa. É o nosso encontro que nos interessa, o que juntos conseguimos problematizar e produzir para inverter os modos acostumados de pensar, de educar, de teorizar, de produzir, de compor a vida. Assumimos, dessa forma, que as potencialidades dessas redes colaborativas de formação docente em sensibilidade aos movimentos infantis foram possíveis pela escolha metodológica de pesquisar com os cotidianos escolares, ao tratar de modo horizontal seus diferentes sujeitos e instituições que compõem o dentro-fora do CMEI. Nessa rede, reconhecemos especialmente os modos como ampliamos nossas formações e compreensões sobre o que podem as crianças.

Diferentemente do que buscam as orientações do governo atual ao propor uniformizar uma orientação comum curricular, as redes de conhecimentos, experiências, linguagens, afecções, saberes, fazeres da escola e da vida, inventadas no cotidiano escolar, em atenção aos seus sujeitos, são importante estratégia para a renovação dos currículos e dos processos de formação de professores(as) nos seus espaços-tempos de produção cotidiana. Desse modo, interessa-nos mais percorrer os processos curriculares cotidianos do que fixar compreensões, uma vez que nosso entendimento de currículos-formações como redes de conhecimento se afasta de um modelo centrado em habilidades e competências do desenvolvimento das crianças, que reduz o trabalho docente às demandas técnicas de aplicação de listas de conteúdos.

\section{(In)conclusões}

A pretensão de compreender e classificar todas as coisas é uma herança do discurso hegemônico da ciência moderna. O currículo e a formação têm sido alvos de muitas teorias, investigações, hierarquizações e sistematizações que objetivam representar um dado modo padrão de se pensar esses campos. No entanto, a todas essas tentativas que, sem dúvida, ainda permanecem, novos discursos 
têm sido produzidos a partir de outros intercessores teóricos, a partir de outras composições envolvendo diretamente os sujeitos que praticam os cotidianos das escolas-vidas, como é o caso das propostas de pesquisas com os cotidianos.

Cada vez mais, temos assumido que qualquer pretensão de se engessar sentidos ou de se estabelecer trilhos de pensamento a serem seguidos é, sumariamente e a todo tempo, violada pelos movimentos das redes cotidianas de saberesfazeres dos sujeitos pesquisados, que produzem danças e deslizamentos de significados impossíveis de serem previstos ou controlados (FERRAÇO, 2006).

Com isso, faz-se necessário afirmar permanentemente que as vidas das crianças estão presentes nas escolas e, desse modo, conferir visibilidade aos movimentos infantis empreendidos por elas e por suas redes de sentidos. Elas trazem suas ansiedades por quererem falar do que acontece fora dali, sua necessidade de brincar com os colegas que encontram todos os dias na escola, sua intenção de ter mais intimidade com alguns adultos que delas cuidam nesse lugar, sua vontade de dizer o que pensam sobre as coisas, sua indignação em cumprir atividades descontextualizadas com o que lhes importa, suas diferentes temporalidades intensivas na relação com os colegas e com os materiais disponíveis. Esses também são movimentos importantes que ampliam os sentidos de currículo e da formação só possíveis de serem problematizados com as crianças e em pesquisas com os cotidianos vividos por elas.

Assim, compreendemos a necessidade de não classificar, julgar, desqualificar ou negligenciar as produções dos educadores e dos alunos das escolas em suas práticas cotidianas, mas, ao contrário, assumi-las como pistas fundamentais para o entendimento das negociações e/ou hibridismos feitos entre currículo e formação pelos sujeitos praticantes, evidenciando, desse modo, a complexidade e a diferença que permeiam suas redes de conhecimentos (FERRAÇO; NUNES, 2012).

Trata-se de entender a pesquisa também como movimento de potencialização dos encontros, das experiências, das negociações, das relações e das afecções, tendo como campo problemático as múltiplas redes tecidas com os praticantes dos diferentes espaços-tempos cotidianos. Essa atitude implica assumir que qualquer tentativa de produção de dados e/ou de investigação com os cotidianos só faz sentido, só se justifica se, direta ou indiretamente, pudermos assumir como princípio básico o envolvimento/inclusão de todos e todas que praticam-vivem esses cotidianos pensados em suas complexidades. Com isso, mais do que sujeitos/objetos de nossas pesquisas, as crianças são, de fato, corresponsáveis e coautoras de nossas questões de investigação à medida que protagonizam práticas-teorias que expressam micropolíticas educacionais.

\section{REFERÊNCIAS}

ALVES, N. Decifrando o pergaminho: os cotidianos das escolas nas lógicas das redes cotidianas. In: ALVES, N.; OLIVEIRA, I. B. (Org.). Pesquisa nos/dos/com os cotidianos das escolas: sobre redes de saberes. Petrópolis, RJ: DP et Alii, 2001. p. 13-38.

BARROS, Manoel de. O livro das ignorãnças. Rio de Janeiro: Record, 1993.

BRASIL. Ministério da Educação. Secretaria de Educação Básica. Critérios para um atendimento em creches que respeite os direitos fundamentais das crianças. Brasília, DF: MEC/SEB/Unesco, 2009a.

. Ministério da Educação. Secretaria da Educação Básica. Indicadores da qualidade na educação infantil. Brasília: MEC, SEB, 2009b.

Ministério da Educação. Secretaria de Educação Básica. Orientações sobre convênios entre secretarias municipais de educação e instituições comunitárias, confessionais ou filantrópicas sem fins lucrativos para a oferta de educação infantil. Brasília, DF: MEC/SEB, 2009c.

Ministério da Educação. Secretaria de Educação Básica. Política de educação infantil no Brasil: relatório

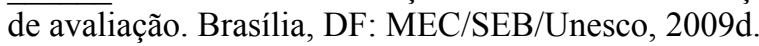

Ministério da Educação. Secretaria de Educação Básica. Diretrizes Curriculares Nacionais para a Edu- 
cação Infantil. Brasília, DF: MEC/SEB, 2010.

Ministério da Educação. Secretaria da Educação Básica. Fundamentos Pedagógicos e Estrutura Geral da BNCC. Brasília, DF, 2017.

CARVALHO, Janete Magalhães. A razão e os afetos na potencialização dos "bons encontros" no currículo escolar: experiências cotidianas. In: FERRAÇO, Carlos Eduardo (Org.). Currículo e educação básica: por entre redes de conhecimento, imagens, narrativas, experiências e devires. Rio de Janeiro: Rovelle, 2011. p. 103-122.

Potência do "olhar" e da "voz" não dogmáticos dos professores na produção dos territórios curriculares no cotidiano escolar do ensino fundamental. In: RJ: DP et Alii, 2012. p. 15-48. (Org.). Infância em territórios curriculares. Petrópolis,

CERTEAU, Michel de. A invenção do cotidiano: Artes de fazer. Petrópolis, RJ: Vozes, 1994. v. 1.

DELEUZE, Gilles. Lógica do sentido. São Paulo: Perspectiva, 2009.

DELEUZE, Gilles; GUATTARI, Félix. Mil platôs: capitalismo e esquizofrenia. Tradução de Aurélio Guerra Neto e Célia Pinto Costa. Rio de Janeiro: Ed. 34, 1996. v. 3.

DELEUZE, Gilles; PARNET, Claire. Diálogos. Lisboa: Relógio D’Água, 2004.

FERRAÇO, C. E. Currículo, formação continuada de professores e cotidiano escolar: fragmentos de complexidade das redes vividas. In:

Cortez, 2005. p. 15-42.

(Org.). Cotidiano escolar, formação de professores(as) e currículo. São Paulo:

Os sujeitos das escolas e a complexidade de seus fazeressaberes: fragmentos das redes tecidas em pesquisas com o cotidiano. In: GARCIA, Regina Leite; ZACCUR, Edwiges (Org.). Cotidiano e diferentes saberes. Rio de Janeiro: DP\&A, 2006. p. 151-180. 2007.

Pesquisa com o cotidiano. Revista Educação e Sociedade, Campinas, SP, v. 28, n. 98, p. 73-95, jan./abr.

FERRAÇO, Carlos Eduardo; NUNES, Kezia Rodrigues. Currículos, culturas e cotidianos escolares: afirmando a complexidade e a diferença nas redes de conhecimentos. In: FERRAÇO, Carlos Eduardo; CARVALHO, Janete Magalhães (Org.). Currículos, pesquisas, conhecimentos e produção de subjetividades. Petrópolis, RJ: DP et Alii, 2012. p. 71-102.

. A tessitura de experiências compartilhadas, negociadas e potencializadas no currículo no ensino superior. Revista Educação, Porto Alegre, v. 34, n. 3, p. 376-384, set./dez. 2011.

GOODSON, Ivor. Currículo: teoria e história. Petrópolis, RJ: Vozes, 1995.

JOSGRILBERG, Fábio B. Cotidiano e invenção: os espaços de Michel de Certeau. São Paulo: Escrituras, 2005.

KOHAN, Walter. Infância, estrangeiridade e ignorância: ensaios de filosofia e educação. Belo Horizonte: Autêntica, 2007.

LARROSA, Jorge. Notas sobre a experiência e o saber da experiência. Revista Brasileira de Educação, n. 19, p. 20-28, jan./abr. 2002.

LEAL, Bernardina. Janela. In: KOHAN, Walter; XAVIER, Ingrid M. (Org.). Abecedário de criação filosófica. Belo Horizonte: Autêntica, 2009. p. 151-156.

LÓPEZ, Maximiliano Valério. Acontecimento e experiência no trabalho filosófico com crianças. Belo Horizonte: Autêntica, 2008.

NUNES, Kezia Rodrigues. Infâncias e educação infantil: redes de sentidosproduções compartilhadas nos currículos e potencializadas na pesquisa com as crianças. 2012. 228 f. Tese (Doutorado em Educação) - Universidade Federal do Espírito Santo (UFES), Vitória, 2012.

OLARIETA, Beatriz Fabiana. O que torna infantil uma literatura ou sobre o papel da literatura nas experiências de filosofia com criança. 2008. 228 f. Dissertação (Mestrado em Educação) - Programa de Pós-Graduação em Educação da Universidade do Estado do Rio de Janeiro (UERJ), Rio de Janeiro, 2008.

OLIVEIRA, Inês Barbosa. Aprendendo nos/dos/com os cotidianos a ver/ler/ouvir/sentir o mundo. Revista Educação e Sociedade, Campinas, SP, v. 28, n. 98, p. 47-72, jan./abr. 2007. 
RIGER, Leila Lurdes Gerlach. O riso na prática de filosofia com crianças. 2006. 100 f. Dissertação (Mestrado em Educação) - Programa de Pós-Graduação em Educação da Universidade do Estado do Rio de Janeiro (UERJ), Rio de Janeiro, 2006.

SAYÃO, Déborah Thomé. A hora de... a educação física na pré-escola. In: CONGRESSO BRASILEIRO DE CIÊNCIAS DO ESPORTE, 10., 1997, Goiânia. Anais... Goiânia: Universidade Federal de Goiás, 1997. v. 1. p. 261-268.

TERIGI, Flávia. Notas para uma genealogia do curriculum escolar. Revista Educação \& Realidade, Porto Alegre, v. 21, n. 1, p. 159-186, 1996.

Recebido em: 08/01/2018

Aprovado em: 15/03/2018 